\title{
Changes in the ultrastructure of gall bladder epithelium in rabbits with experimental gallstones
}

\author{
A. F. HAYWARD, J. W. FRESTON, AND I. A. D. BOUCHIER \\ From the Royal Dental Hospital of London, School of Dental Surgery, and the \\ Department of Medicine, Royal Free Hospital, London
}

The mucus-secreting activity of the gall bladder epithelium is normally subject to species variation (Hayward, 1968). Electron microscopic studies indicate definite evidence of secretory material in human gall bladder epithelial cells (Wolf-Heidegger, Stäubli, and Hess, 1965), but there is no histological or ultrastructural evidence for mucus secretion in the rabbit gall bladder under normal conditions. During the experimental induction of gallstones in the rabbit there is an increase in the content of biliary mucus (Freston, 1967). The origin of this mucus is of some interest. Light microscopic studies suggest that the material is produced by the gall bladder epithelium and therefore an electron microscopic study has been undertaken to seek support for this view.

\section{MATERIALS AND METHODS}

The method of inducing gallstones will be described in detail in another communication (Freston and Bouchier, in preparation). Male and female New Zealand rabbits weighing 1,500 to $2,000 \mathrm{~g}$ were maintained in individual cages and received water ad libitum. Control animals were fed a daily ration of $100 \mathrm{~g}$ Purina rabbit chow pellets. Test animals received in addition $0.75 \%(w / w)$ of dihydrocholesterol (kindly given by the Schering Corporation) which was mixed into the diet. On this regimen some animals form gallstones after seven days of feeding, and by the ninth day all the animals have stones, which are composed of insoluble salts of glycine-conjugated allodeoxycholic acid (Hofmann and Mosbach, 1964).

The gall bladders were removed from paired groups of animals while under pentobarbital anaesthesia. Tissue was obtained after dihydrocholesterol had been fed for three, five, 12, and up to 27 days.

The fundus of the gall bladder was fixed in buffered $1 \%$ osmium tetroxide solution, washed, dehydrated in methanol, and embedded in Araldite. Thin sections were stained with uranyl acetate in methanol or aqueous lead citrate and examined in the AEI EM6 electron microscope. Survey phase-contrast light microscopy was used for orientation purposes on thicker sections from resinembedded tissue.

\section{RESULTS}

NORMAL CONTROLS The ultrastructure of the gall bladder of normal rabbits did not differ in any way from that already described (Kaye, Wheeler, Whitlock, and Lane, 1966; Hayward, 1966). Some important relevant features are reiterated to facilitate comparison with the experimental animals.

The epithelial cells have an apical microvillous border beneath which is a broad band of cytoplasm, the apical zone, containing only granular ground substance and an occasional small vesicle (Fig. 1). The main concentration of mitochondria lies between the apical zone and the nucleus. The Golgi apparatus is not prominent, comprising three or four parallel flattened cisternae and some peripheral vesicles near the upper pole of the nucleus. As seen in section it may represent part of a ring of Golgi material round the nucleus. The supra- and infra-nuclear cytoplasm also contains small numbers of lysosome-like and multivesicular bodies about $1 \mu$ in diameter. They cannot be related structurally to any other organelle.

The intercellular spaces contain a network of long processes resembling microvilli. The spaces are variable, especially in the degree of dilatation, a feature known to depend on the functional state of the mucosa (Kaye et al, 1966). Some of the epithelial cells appear as dark cells. They are narrow, perhaps compressed or shrunken and have a very high overall electron density. As a result, their internal ultrastructure is obscured. Small round cells, which are probably infiltrating leucocytes, sometimes occur between the epithelial cells near an intact basement membrane.

APPEARANCE AFTER THREE TO FIVE DAYS OF EXPERIMENTAL DIET At this stage no stones are visible in the bile, either macroscopically or with the aid of a light microscope.

The histology remains undisturbed but some of the epithelial cells show a change in cytoplasmic ultrastructure. The apical zone of cytoplasm is reduced in width, with an increased number of vesicles. Small round vesicles occur throughout the supranuclear cytoplasm (Fig. 2). In a few cells at three days and in a greater number at five days, 


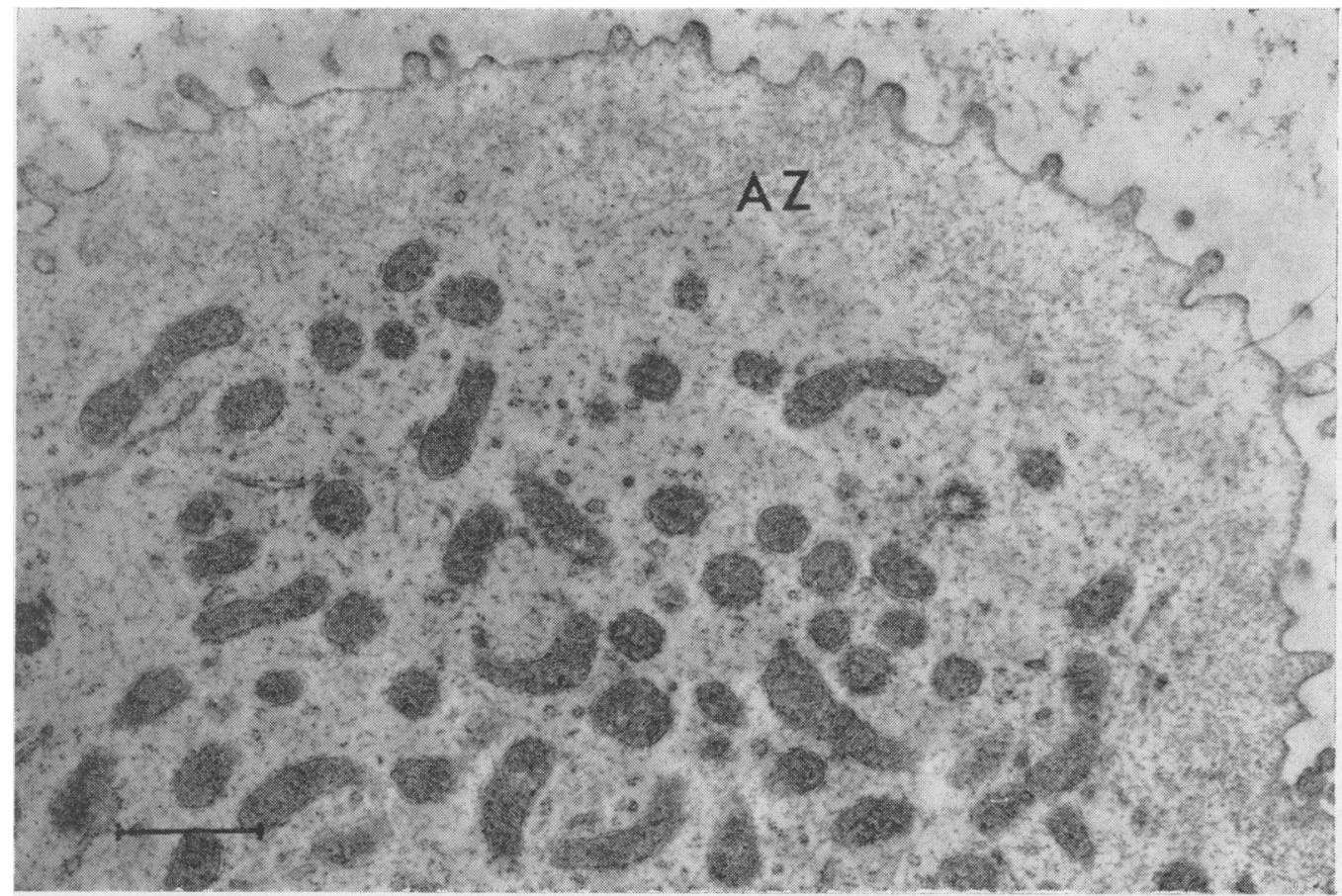

The magnification is indicated on each figure by a scale line representing 1 micron.

FIG. 1. Apical part of a gall bladder epithelial cell from a normal rabbit. Numerous mitochondria occur below a granular apical zone $(A Z)$. There are few vesicles in the normal cell.

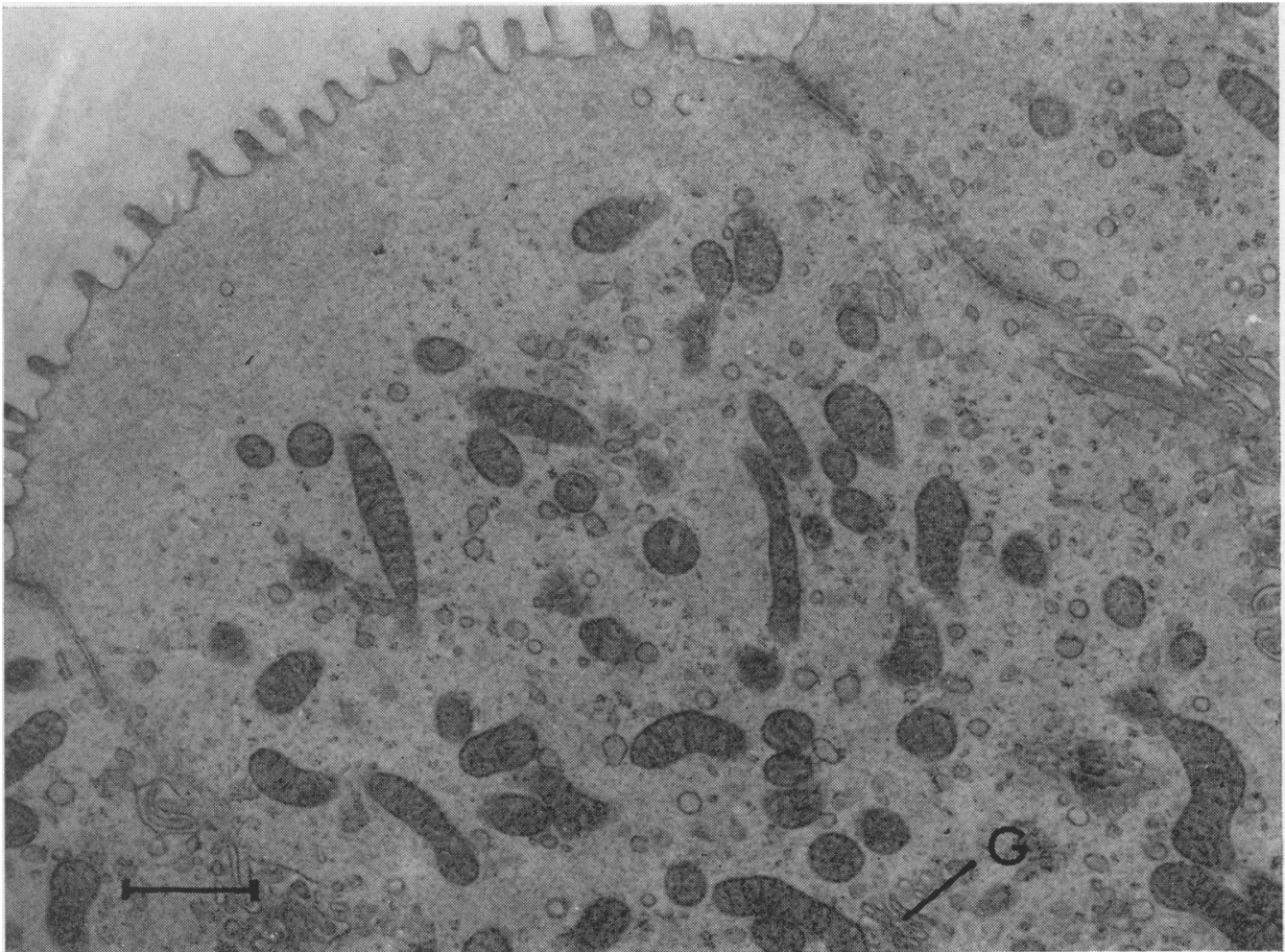

FIG. 2. Apical part of a gall bladder epithelial cell from a rabbit after three days on dihydrocholesterol. Numerous small round vesicles occur in the cytoplasm with a few in the apical zone. G-Golgi apparatus. 


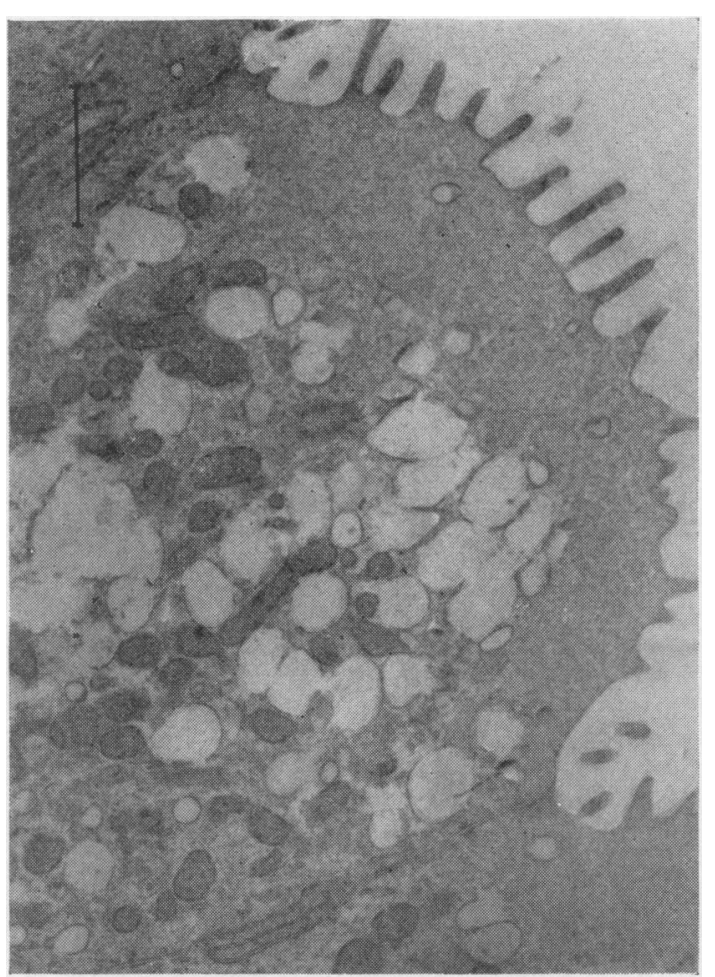

FIG. 3 .

FIG. 3. After five days on the diet some cells show closepacked clear droplets resembling mucus. Several groups are confluent with poorly preserved outlines. They do not extend into the apical zone.

FIG. 4. The epithelium after 12 days of diet showing multilayering of the cells. $V=$ intercellular vacuoles with microvilli. $B L=$ basal lamina. $I=$ dilated intercellular spaces.

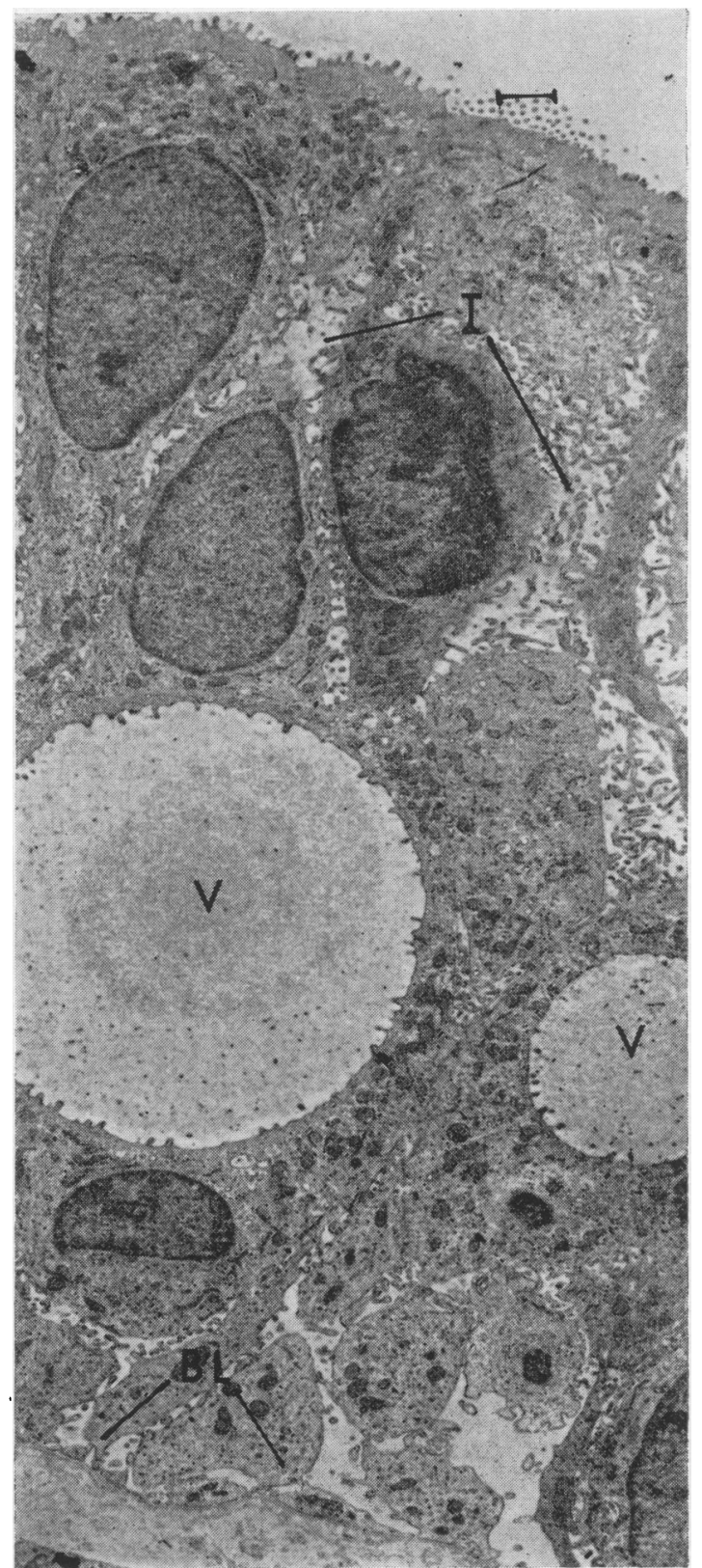

FIG. 4. 


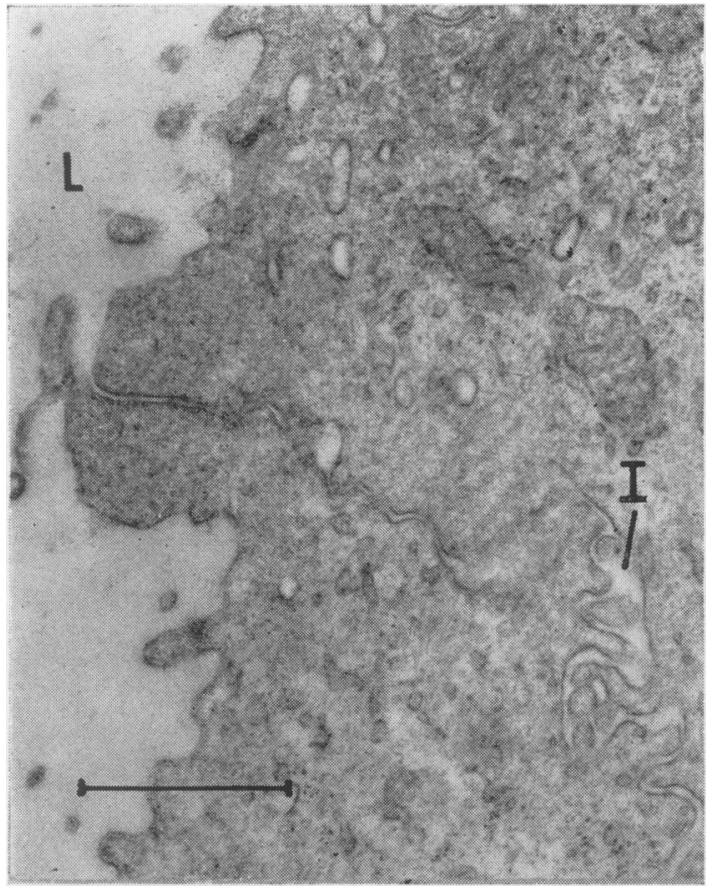

FIG. 5.

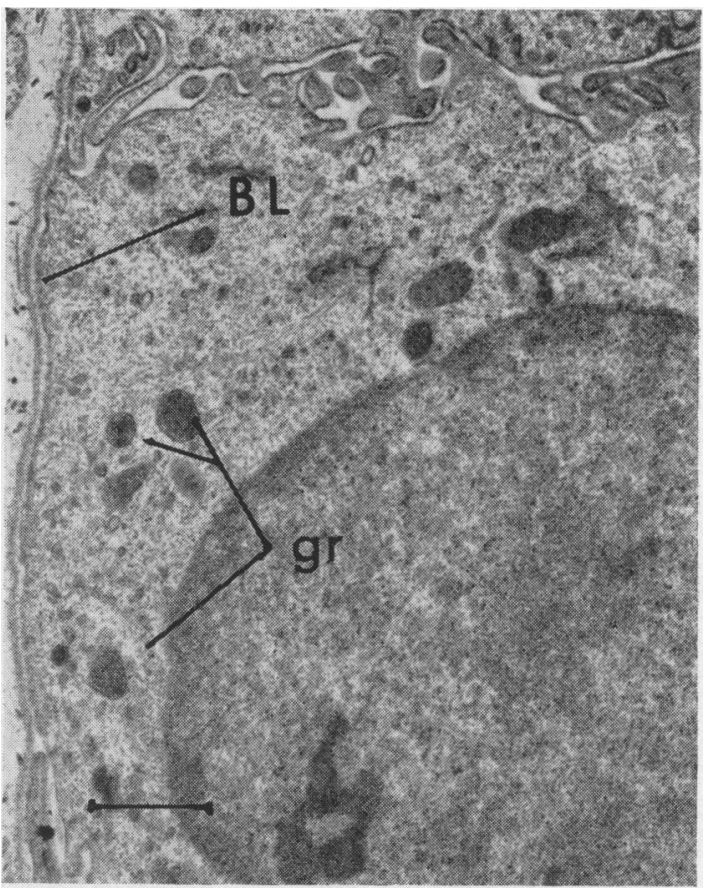

FIG. 6 .

FIG. 5. The junction between two epithelial cells at the boundary of an intercellular vacuole. The intercellular space $(I)$ does not open freely into the vacuole lumen $(L)$ but is separated from it by a terminal bar-like structure.

FIG. 6. The basal part of an epithelial cell from rabbit after 12 days of the experimental diet. Small granules of about $0.25 \mu$ diameter are present $(\mathrm{gr})$ and may represent primary lysosomes. They have not been seen in normal cells. $B L=$ basal lamina.

larger droplets occur in the supranuclear cytoplasm. They are about $0.5 \mu$ in diameter with electrontranslucent contents. The limiting membrane may be discontinuous with the free ends curled back. The droplets accumulate beneath the apical zone without extending into it (Fig. 3) and similar, smaller droplets occur near the nucleus. They have not been found in association with the Golgi apparatus at this stage.

TWELVE-DAY DIET After a further week on the dihydrocholesterol diet masses of sand-like stones are readily visible in the bile contained in the gall bladder. The cellular lining is no longer a simple columnar epithelium (Fig. 4). Many of the component epithelial cells do not extend from basement membrane to the apical surface in any one section. Even when the basement membrane is sectioned at right angles, thus showing a single well-defined line, nuclei are seen at all levels from the base to quite near the luminal surface. An artefact of sectioning can be excluded. In oblique sections of a single cell layer the basement membrane is diffuse, and, though there may be more than one line of nuclei, they always lie nearer the base so that there is a substantial layer of apical cytoplasm in which nuclei are absent.

The specimens at 12 days show patches of epithelium of an increased thickness with clumps of cells protruding into the lumen (Fig. 4). The appearance is related to another abnormal feature of the tissue. Large circular spaces occur between the epithelial cells. They are probably spherical in shape. They do not communicate with the ordinary intercellular spaces and are completely surrounded by epithelial cells joined by structures resembling terminal bars (Fig. 5). These intercellular vacuoles are lined by microvilli similar to those of the apical border of the epithelial cells. Their contents are mainly electron translucent but there is a central mass of finely granular material with a denser core. Larger granules, $200 \AA$ in diameter, are scattered sparsely through the vacuole contents. Occasionally a large vacuole has an bilobed appearance with an equatorial constriction as if two adjoining spaces had fused. The round intercellular vacuoles are found where the epithelium is multilayered. Figure 4 


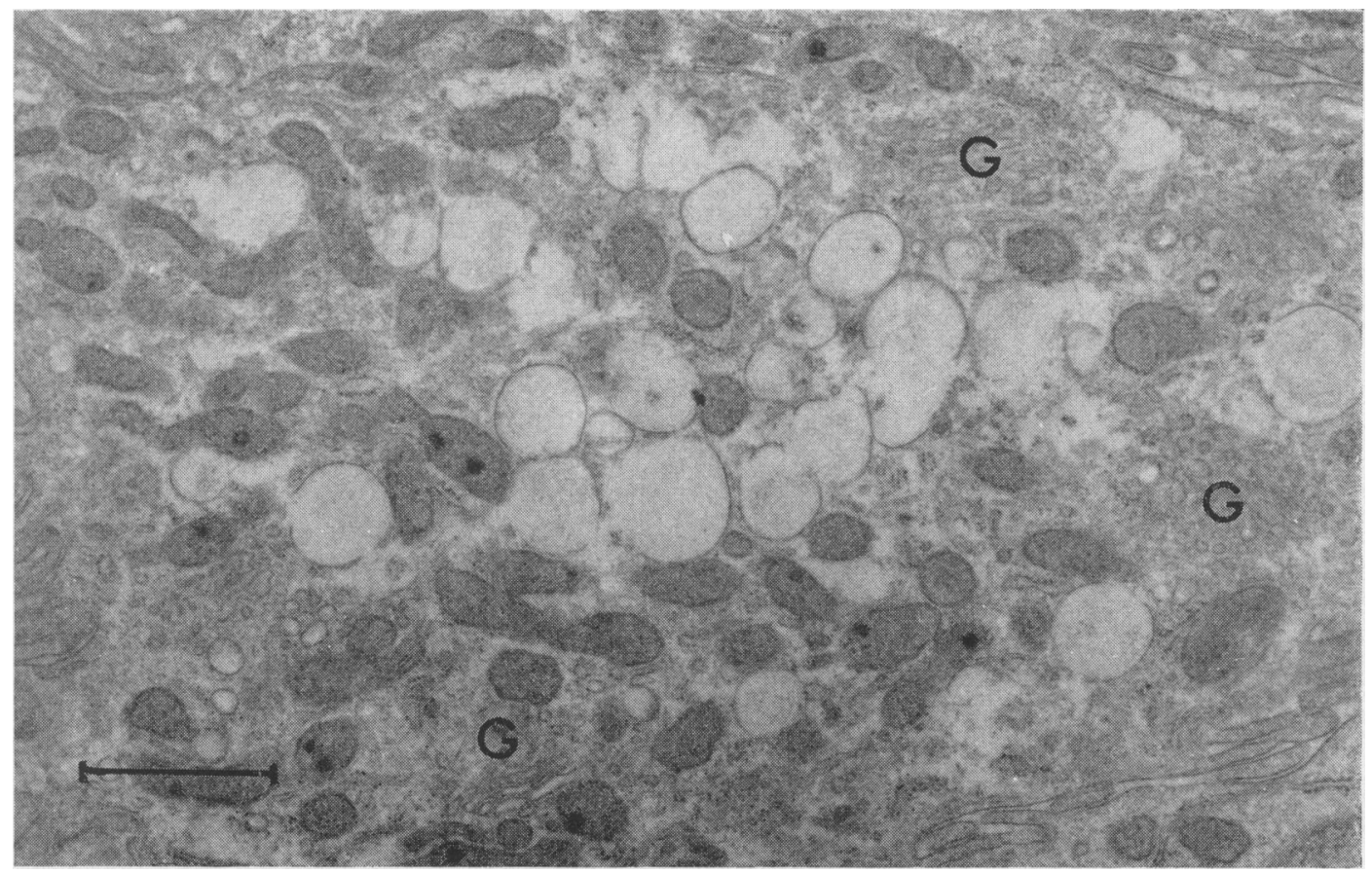

FIG. 7. Intracellular droplets in the vicinity of the Golgi apparatus $(G)$ after 12 days of the diet. Attention is drawn to this association because of the part known to be taken by the Golgi apparatus in other secretory systems. There is no evidence for a structural relationship in these cells.

shows a typical example. The epithelial cells lying between the vacuoles and the gall bladder lumen have no contact with the basement membrane. No cell has been observed with microvillous borders facing both the lumen and an intercellular vacuole. A line drawn from the lumen of a vacuole to the lumen of the gall bladder always crosses at least two cells, often more than two. One of the cells is usually attenuated to form a thin shell consisting of the microvillous border of the vacuole and an adjacent granular layer of cytoplasm.

The epithelial cells between an intercellular vacuole and the basement membrane are often closely packed narrow columns of cytoplasm lying parallel to each other and obliquely to the basement membrane. Elongation and distortion of cells is also seen in the absence of an intercellular vacuole.

Dark cells with cytoplasmic characteristics similar to those found in normal gall bladder are frequently found in the pathological material. They are even narrower than normal and sometimes appear to be subdivided into tubes of cytoplasm running between two other cells in close apposition. In other situations they may be surrounded by abnormally dilated intercellular spaces.

The cytoplasmic changes found at five days are even more pronounced at 12 days. The supranuclear region of most of the epithelial cells is filled with translucent droplets and mitochondria. The droplets do not penetrate the clear apical zone but remain closely packed along its lower border. They impart a foamy appearance to the cells. The outer membranes of the droplets are frequently discontinuous.

The droplets occur near the nucleus, around its apical pole, and in the immediate vicinity of the Golgi apparatus (Fig. 7). The Golgi apparatus is extensive and is composed of lamellae and a large number of small vesicles. There is no evidence of a structural association between the droplets and the Golgi apparatus.

In the pathological specimens it is quite common to see a cell which has disintegrated or degenerated with loss of cytoplasmic substance and of the continuity of the plasma membrane. One or two cytolysosomes have been seen but up to 27 days on the diet they are not a striking feature of the epithelium.

In the basal part of the epithelial cells after 12 days on the diet, electron-dense granules of about $0.25 \mu$ diameter can occasionally be observed (Fig. 6). They are always within a few microns of the basement membrane.

The changes in the gall bladder epithelium are not 
uniform and in some areas epithelial cells are indistinguishable from normal. Feeding the lithogenic diet for up to 27 days has resulted in no further ultrastructural changes. At no stage did the epithelium exhibit an inflammatory response to the diet or the resulting gall stones.

\section{DISCUSSION}

The results of electron microscopic examination of the gall bladders of rabbits with dihydrocholesterol stones confirms and amplifies the results of light microscopic and biochemical studies (Freston and Bouchier, in preparation), and suggest that the cells produce mucus when gallstones are induced. The epithelial cells are quite different from those of normal rabbits and resemble the 'mucoid' cells of other tissues (Helander, 1962). Mucus cells occur widely in the gall bladders of other species and have been demonstrated by histological methods (Ott, 1937; Harding, 1934), by histochemistry (Yamada, 1962; Tusques, Senelar, Ginguene, and Vaugien, 1964), and by electron microscopy (Johnson, McMinn, and Birchenough, 1962; Hayward, 1965; Wolf-Heidegger et al, 1965). So far as we are aware mucus secretion has not been demonstrated in the normal rabbit gall bladder.

The conclusion that mucoid cells occur in this condition rests on ultrastructural observations and is well supported by the biochemical findings. Biliary mucus substances show an increase at the same time as mucoid cells appear which is before stones form. The rapid increase of mucus after stone formation is accompanied by an increase in the number of mucoid cells.

This combination of the findings suggest that under the conditions of this diet, mucus synthesis is stimulated in the gall bladder epithelium of the rabbit. An otherwise non-secretory epithelium is induced to become mucoid. The mechanism of release of the synthesized products into the bile is not known. The electron micrographs give no evidence of release of discrete droplets. In almost all cases the droplets are separated from the apical plasma membrane by the intact apical clear zone of the cells. It is possible that under these abnormal conditions mucus is released by the sloughing of cells from the surface and their subsequent disintegration.

Observations made in species whose gall bladder normally secretes mucus have suggested a change in quantity or type of secretion in the presence of gallstones. An increased concentration of mucous substances in the bile has been reported in human cholelithiasis (Bouchier, Cooperband, and El Kodsi, 1965; Bouchier and Cooperband, 1965; Verschure, 1956). There is also histological evidence of increased mucus secretion in the surface cells and in the crypts and ducts (Elfving, 1960; Delaquerrière, Tremblay, and Riopelle, 1962). The gall bladder of the dog is normally lined by mucoid cells (Johnson et al, 1962) but develops goblet cells when stones or foreign bodies are present (Bauer and Hakki, 1932).

The development of mucus secretion in the rabbit gall bladder epithelium is therefore assessed against the background of mucus secretion in other species. The cells may be looked upon as potentially mucussecreting but normally inactive. Thus the change is less dramatic than the qualitative mucous metaplasia of some tumours or the squamous metaplasia of epithelia in vitamin A deficiency and may result from a modification of mature cells rather than from growth and development of undifferentiated cells.

The nature of the stimulus or irritant in this experimental system is not known for certain. The concentration of mucous substances increases and mucoid cells are present before stones form so that the change is not initiated by mechanical irritation. No doubt the subsequent acceleration of the change results from such irritation. The initial stimulus must therefore be chemical. When the cystic duct is tied before the diet is administered no change in gall bladder mucus is detectable biochemically (Freston and Bouchier, in preparation). It is possible that the earliest stimulus is the allodeoxycholic bile salts present in bile which act directly on the epithelium. The mechanism of action of these abnormal bile salts is unknown but they may enter the cells by diffusion or by pinocytosis which is known to occur in the gall bladder (Hayward, 1962; Kaye et al, 1966).

The piling up of epithelial cells suggests a degree of increased cell proliferation or hyperplasia. Jacoby (1953) reported an increased number of mitoses with stratification of the epithelium after ligation of the common bile duct in the guinea pig.

The basal granules found in the experimental epithelium are not found in the normal adult gall bladder but do occur during development (Hayward, 1966). They resemble the primary lysosomes of other undifferentiated epithelia (Moe, Rostgaard, and Behnke, 1965; Hayward, 1967). It is possible that they indicate the presence of a greater proportion of immature cells in this experimental condition. There is no evidence for their participation in any cellular process such as pinocytosis or its sequelae.

The large round intercellular vacuoles correspond to PAS-positive structures observed by light microscopy (Freston and Bouchier, in preparation). The lining of microvilli and the peripheral terminal bars, together with the fact that though the adjacent cells often extend to the basement membrane they never reach the lumen, suggests that the limiting membrane 
represents the apical plasma membrane of the epithelial cells. The cells at the base have failed to adapt to multilayering of the epithelium and retain an apical microvillous border. The smooth circular outline of the vacuoles and the compression of adjacent cells suggests an increased hydrostatic pressure. The intercellular vacuoles might be regarded as miniature retention 'cysts'.

The dark cells of the gall bladder are probably concerned with water transfer across the epithelium (Kaye, cited by Hayward, 1968) and their exaggerated form in the specimens containing gallstones could be due to an as yet undetermined disturbance of the normal physiology. A study is being undertaken of gall bladder epithelial function in the presence of dihydrocholesterol-induced gallstones.

\section{SUMMARY}

The normal rabbit gall bladder does not contain mucus-secreting cells. When rabbits are fed a diet containing dihydrocholesterol, gallstones develop in seven to nine days. The stones are associated with the appearance in the bile of mucus which apparently originates in the gall bladder epithelium.

Within three days of the dihydrocholesterol being fed and before the development of stones, intracellular droplets resembling mucus are observed in the epithelial cells. Intercellular vacuoles later make their appearance. They are lined by microvilli similar in appearance to the microvilli of the cell apices.

Other changes include the heaping up of epithelial cells and the presence of basal granules, possibly indicating increased cell production and the presence of more immature cells.

This investigation was supported by a US Public Health Service fellowship from the Institute of Arthritis and Metabolic Diseases (J.W.F.) and by grants from the Medical Research Council and the R. Franklin Carter Foundation Inc. (I.A.D.B.). The electron microscope was made available by the Wellcome Trust and further financial support by the Nuffield Foundation.

\section{REFERENCES}

Bauer, R., and Hakki, A. C. (1932). Le mucus de la vésicule biliaire. Presse méd., 40, 650-653.

Bouchier, I. A. D., and Cooperband, S. R. (1965). The characteristics of 'white bile'. Gastroenterology, 49, 354-359.

- - , and El Kodsi, B. M. (1965). Mucous substances and viscosity of normal and pathological human bile. Ibid., 49, 343-353.

Delaquerrière, L., Tremblay, G., and Riopelle, J. L. (1962). Argentaffine cells in chronic cholecystitis. Arch. Path., 74, 142-151.

Elfving, G. (1960). Crypts and ducts in the gallbladder wall. Acta path. microbiol. scand., 49, suppl. 135.

Freston, J. W. (1967). Ph.D. Thesis. University of London.

Harding, H. E. (1934). The secretion of mucus by the epithelial cells of the gall-bladder, and the experimental production of mucocele. Brit. J. Surg., 22, 355-364.

Hayward, A. F. (1962). Electron microscopic observations on absorption in the epithelium of the guinea pig gall bladder. Z. Zellforsch., 56, 197-202.

- (1965). The fine structure of the gall bladder epithelium of the sheep. Ibid., 65, 331-339.

- (1966). An electron microscopic study of the developing gall bladder epithelium in the rabbit. J. Anat. (Lond.), 100, 245-259.

- (1967). Changes in fine structure of developing intestinal epithelium associated with pinocytosis. Ibid., 102, 57-70.

- (1968). The structure of gall bladder epithelium. Int. Rev. gen. exp. Zool., 3, 205-237.

Helander, H. F. (1962). Ultrastructure of fundus glands of the mouse gastric mucosa. J. Ultrastruct. Res., Suppl. 4.

Hofmann, A. F., and Mosbach, E. H. (1964). Identification of allodeoxycholic acid as the major component of gallstones induced in the rabbit by $5 \alpha$-cholestan-3 $\beta$-ol. J. biol. Chem., 239, 28132821.

Jacoby, F. (1953). Mitotic activity in the gall bladder epithelium of the guinea pig after ligation of the common bile duct. $J$. Physiol. (Lond.), 119, 21-22P.

Johnson, F. R., McMinn, R. M. H., and Birchenough, R. F. (1962). The ultrastructure of the gall-bladder epithelium of the dog. J. Anat. (Lond.), 96, 477-487.

Kaye, G. I., Wheeler, H. O., Whitlock, R. T., and Lane, N. (1966). Fluid transport in the rabbit gall-bladder. J. Cell Biol., 30, 237-268.

Moe, H., Rostgaard, J., and Behnke, O. (1965). On the morphology and origin of virgin lysosomes in the intestinal epithelium of the rat. J. Ultrastruct. Res., 12, 396-403.

Ott, H. (1937). Das Gallengangssystem des Schweins. Z. Anat. Entwgesch., 107, 7-17.

Tusques, J., Senelar, R., Ginguene, Y., and Vaugien, M. (1964). Etude histochimique sur les vésicules biliaires de mouton et de cobaye: les mucopolysaccharides. Ann. Histochim., 9, 269-276.

Verschure, J. C. M. (1956). Electro-chromograms of human bile. Clin. chim. Acta, 1, 38-48.

Wolf-Heidegger, G., Stäubli, W., and Hess, R. (1965). Zur Ultrastruktur und Histochemie der Gallenblasenschleimhaut des Menschen und der Katze. Acta anat. (Basel), 62, 606-618.

Yamada, K. (1962). Morphological and histochemical aspects of secretion in the gall bladder epithelium of the guinea pig. Anat. Rec., 144, 117-128. 